\title{
GCU
}

Glasgow Caledonian

University

University for the Common Good

\section{Priority pharmaceutical micropollutants and feasible management initiatives to control water pollution from the perspective of stakeholders in Metropolis of southern Brazil}

Barcellos, Demian Da Silveira; Helwig, Karin; Gervasoni, Ronald; Teedon, Paul; Possetti, Gustavo Rafael Collere; Bollmann, Harry Alberto

Published in:

Integrated Environmental Assessment and Management

DOI:

10.1002/ieam.4301

Publication date:

2020

Document Version

Author accepted manuscript

Link to publication in ResearchOnline

Citation for published version (Harvard):

Barcellos, DDS, Helwig, K, Gervasoni, R, Teedon, P, Possetti, GRC \& Bollmann, HA 2020, 'Priority pharmaceutical micropollutants and feasible management initiatives to control water pollution from the perspective of stakeholders in Metropolis of southern Brazil', Integrated Environmental Assessment and Management, vol. 16, no. 6, pp. 955-967. https://doi.org/10.1002/ieam.4301

\section{General rights}

Copyright and moral rights for the publications made accessible in the public portal are retained by the authors and/or other copyright owners and it is a condition of accessing publications that users recognise and abide by the legal requirements associated with these rights.

Take down policy

If you believe that this document breaches copyright please view our takedown policy at https://edshare.gcu.ac.uk/id/eprint/5179 for details of how to contact us. 


\section{Priority pharmaceutical micropollutants and feasible management initiatives to control water pollution from the perspective of stakeholders in metropolis of southern Brazil}

4

\section{Abstract}

The search for common agreement between stakeholders is one of the biggest challenges for solving environmental problems. There are different views, perceptions, knowledge and sectoral goals for these stakeholders. In complex environmental problems, such as the management of pharmaceutical micropollutants, it is essential to establish the intersectoral and individual sector priorities for a collective approach to the problem. This research aimed to identify priority micropollutants for intervention initiatives, and the management goals of the stakeholders involved in the 'product chain' of pharmaceuticals, in the region of Curitiba, Brazil. First, the most consumed pharmaceutical micropollutants in the region and those previously detected in water were identified and a 'long list' with 40 pharmaceuticals was drawn up for prioritization by stakeholders. Stakeholders of region were selected by intentional sampling and were invited to a workshop that was designed to list, by consensus, priority micropollutants and objectives for their management. The event was attended by 37 stakeholders from different sectors. It was divided into two stages: the first stage was a multisectoral discussion to select the priority pharmaceutical micropollutants; the second stage a sectoral discussion to establish management objectives to control and reduce the presence of these pollutants in waters. The meeting generated a coherent prioritization of pharmaceuticals where ethinyl estradiol, ciprofloxacin, ibuprofen, diclofenac, estradiol, caffeine and fluoxetine were prioritized and their importance was justified. The main sectoral goals prioritized were related with the drug take-back program, characterization of the presence of pharmaceuticals in the sanitation cycle and the creation of a permanent multi-sector discussion environment for the theme. The multisectoral definition, established collectively by consensus, of management priorities is promising and this strategic approach can be replicated in other developing countries.

Key-words: Pharmaceutical micropollutants management Water pollution control environmental management
Prioritization process Water Stakeholder engagement Urban

\section{INTRODUCTION}

Pharmaceuticals are absolutely essential to the medical demands of animals and humans, but paradoxically, the same properties that ensure the therapeutic effects of these substances are those that can cause the toxicity or bioaccumulative potential of their traces in the environment (Halling-Sørensen et al. 1998; Santos et al. 2010). Exposure to traces of medical substances, intentionally or unintentionally released into the environment, has received attention worldwide. The problem was initially highlighted in the 1970s in the USA and about a decade later in the United Kingdom, 
with advances in analytical techniques for detection and laboratory measurement (Santos et al. 2010). But it was from the mid-1990s that investigations on the subject were intensified, showing cause-effect responses of these residues on the environment and human health (Kümmerer 2009; Qian et al. 2015; Tiedeken et al. 2017). At present, the focus is primarily on urban rivers, since the characteristics of the 'product chain' (Helwig 2018, p.200) of pharmaceutical production and consumption are most likely to result in high concentrations of residue where high population densities and low environmental dilution co-occur (Helwig 2016). Since in Brazil only $46 \%$ of the sewage is treated and only 21 municipalities, all located in the 100 largest cities in the country, treat more than $80 \%$ of the sewage (SNIS 2018), the priority of the sanitation sector is still focused on the removal of macropollutants, i.e. dissolved organic carbon, nitrogen and phosphorus, from industrial and household effluents. Among the group of micropollutants, the demands of the productive sector (agriculture and industry) for agrochemicals and metals has led to those residues being considered priorities for the national context. A previous study (Barcellos et al. 2019a, p. 76), carried out with 32 stakeholders from different sectors of society (community, academia, government and productive sector) in the Curitiba/Brazil region, showed that the most important aquatic micropollutants are pesticides, followed by heavy metals and then pharmaceuticals.

There are already management initiatives for agrochemicals and heavy metals in the waters in Brazil, implemented via legal instruments that establish limits for the maximum permissible concentrations of these compounds both in natural waters (Brazil 2005) and water supply systems (Brazil 2017). Despite an emerging scientific consistency in the international literature on the environmental effects of some pharmaceutical compounds, such as 17-alpha ethinylestradiol (Owen and Jobling 2013; Gilbert 2013), there are as yet no regulations and standards to drive monitoring, control and minimization of its residues in Brazil. This is largely true elsewhere in the world as well, although several pharmaceuticals are on the EU 'Watch List' and Article $8 \mathrm{c}$ of Directive 2008/105/EC (amended by Directive 2013/39/EU) obliges the European Commission to develop a strategic approach to water pollution from pharmaceutical substances and some countries have started putting in place national regulations (Küster and Adler 2014). As the concentrations of pharmaceuticals reported in Brazilian surface waters have been relatively high, and certain pollutants have indeed also been found in the water supply in significant concentrations (Dias 2014; Böger et al. 2015; Lima et al. 2017; Reis et al. 2019), there is a need to prioritize pharmaceutical substances for monitoring and intervention. Efforts to establish a comprehensive prioritization of pharmaceuticals in Brazil and in developing countries are still incipient (Barcellos et al. 2019b).

Where a lack of data on the range, volume and toxicities of pharmaceuticals consumed hinders a strictly risk-based approach, a mix of published data and 'expert input' can be used as a starting point (Helwig et al. 2013) for the prioritization of pharmaceuticals for monitoring or intervention. In this study, we explore firstly how local stakeholders prioritize pharmaceuticals for the management of urban waters, and from there, we explore options for management initiatives.

The entire management process can be considered collective and needs to be negotiated among the stakeholders. This is no different in the case of pharmaceutical micropollutants. The various groups involved in this issue have distinct and 
complementary overviews, responsibilities and knowledge about the processes involved in the product chain of these pollutants. In order to validate such a collective approach, it is essential that the integration of these perceptions, priorities and manageable initiatives is discussed jointly by all these stakeholders. The topic of pharmaceutical pollution has not been widely discussed in Brazil so far, and in the incipient discussions that have been established, the sectorial nature of approaches and decisions remains (Barcellos et al. 2019a, p. 142). This study sought to bring stakeholders together to further this integration of perspectives in order to bring about a collective approach to management.

\section{MATERIALS AND METHOD}

This study was conducted in the metropolitan region of Curitiba, the ninth largest metropolitan region in Brazil, with about 3.5 million inhabitants (IBGE 2016). Curitiba and the metropolitan region have an integrated water supply system, so that the city's drinking water also comes from the metropolitan region (SANEPAR 2013). Water management in Brazil is the responsibility of Union (national authority) and States (regional authority) while the land use and "to combat pollution in all its forms" is the responsibility of municipalities (Brazil 1988). The city of Curitiba is the capital of the Parana State, has around 2 million inhabitants, is the largest city of southern Brazil and the eighth most populous in the country (IBGE 2019). The city has a world-renowned history of urban planning and management and has won several international awards in recognition of the initiatives in favor of the environment and the quality of life of its citizens (Mega 2010; Macedo 2013). It is also the Brazilian capital with the best basic sanitation in the country, with $94 \%$ sewage coverage, $100 \%$ of treated water supply for the population and $100 \%$ waste collection (SNIS 2018). As such, the city was selected for the possibility of exploring the potential for innovation in management technologies and environmental planning.

A workshop was organized with stakeholders to prioritize pharmaceutical micropollutants, as well as to jointly identify feasible management initiatives. Prior to this workshop, two selection processes was take place: a 'long list' of possible priority pharmaceutical products was drawn up to begin the selection and classification process and presented to stakeholders, and, of course, the stakeholders in the Curitiba region themselves have been identified and approached as potential workshop participants.

\section{Initial pharmaceutical micropollutants long list}

The 'long list' of pharmaceuticals was established with a view to selecting pharmaceuticals that might be likely to be 'priorities for intervention' by participants. Establishment of a 'long list' from thousands of pharmaceuticals available on the market is not straightforward and various criteria, including consumption level, 'expert choice', previous detections, and known toxicities can be used in this process (Helwig et al. 2013). In the current research, two separate approaches were used.

Firstly, in order to represent 'expert choice' and include an element of (perceived) risk to the environment, the literature was reviewed to determine which pharmaceutical micropollutants had been monitored in the rivers of the Metropolitan 
129 Region of Curitiba and to identify minimum and maximum concentrations for these 130 compounds. It was established that only 27 compounds from 8 different classes 131 (hormones, antihypertensives, anti-inflammatories, analgesics, psychotropics, metabolites, lipid regulators, stimulants and food/cosmetics preservatives (Ide et al. 2013; Kramer et al. 2015; Osawa et al. 2015; Böger et al. 2018; Barcellos et al. 2019a, p. 66) had been monitored in this region. Several shortcomings to this first approach are acknowledged. Firstly, the list of pharmaceutical products resulting from review included only those already monitored and detected in surface waters, which represents a tiny fraction of all pharmaceuticals on the market. This constraint is exacerbated by the fact that many researchers, for reasons of convenience, select analytes that have already been reported in the environment - a phenomenon known as the 'Matthew effect' (Merton 1988) - or for which there is a readily available analytical method. Secondly, beyond their detection, there is no attempt to prioritize these substances or to establish their actual environmental risk. Thirdly, the list does not represent in any way the multisectoral interests or concerns of the various stakeholder groups. Nevertheless, as a starting point for discussions, a list of pharmaceuticals detected in the local environment was thought to be useful.

The second approach was based on pharmaceutical consumption patterns and sought to establish which pharmaceuticals are most commonly consumed in the region. Pharmaceuticals may be bought by the general population, freely dispensed by medical staff in Municipal Health Units (MHU) or dispensed and used in hospitals (the pharmaceuticals used and dispensed by hospitals were not considered in this analysis, as there are no data available). The pharmaceutical consumption data in Curitiba used in this research refer to the period of 2016 and 2017 and were extracted from a research already published (Barcellos et al. 2019a, p. 78-99). The level of consumption of a pharmaceutical is a poor indicator of the environmental risk posed by its residues in the environment, which depends on many factors including metabolism (including the extent to which the pharmaceutical is excreted as parent compound or as metabolites), persistence in the environment, potential for bioaccumulation and toxicity. But just like the previous list of compounds already found in water bodies, the list of top-selling and distributed pharmaceuticals is an important starting point, not only because it may allow inference of which pharmaceuticals are likely to be present in the waters but also because they are likely to be familiar to workshop participants.

From these two initial lists, 40 active ingredients of pharmaceutical products were identified as potential priorities for stakeholders (this list can be found in Supplemental Data). The pharmaceuticals selected were those: 1) with a relevant position in the consumption ranking (sale in pharmacies + free distribution in health units); 2) present in the waters of the region in concentration and with possible environmental effects (information evaluated from the study of each molecule by Wiki Pharma data base). Among the 40 selected, 10 active principles had already been monitored and detected in the waters of the region. For the 40 pharmaceuticals selected, information was sought on the percentage excreted unchanged via urine (Bernareggi 1998; Johnson and Williams 2004; Ashley and Currie 2009; Lucena 2013; Cunha 2014; EMC 2017) and the ecotoxicological LOEC - lowest observed effect concentration - (Wiki Pharma 2018) of each compound to make available to stakeholders. This list was sent to all invited stakeholders, who were asked to indicate, 
in their own view, which 10 compounds they considered to be a priority and to bring this list of the 10 along to the workshop. The use of these initials list was designed to guide the discussion, but stakeholders could select other pharmaceuticals that were not included in the lists.

\section{Selection of Stakeholders}

The stakeholders were selected by intentional sampling, following a procedure similar of previous research (Doerr-MacEwen and Haight 2006), we sought participants from two broad groups: those who have contributed to the literature on micropollutants in the region, and those who play a role in the production and consumption of pharmaceuticals and their subsequent management in (waste) waters.

To identify them, an exploratory research was initially carried out for academic papers published by researchers from institutions located in the region of Curitiba. The curricula vitae of these researchers were accessed by 'Lattes Platform' (a system that reports academical and scientific information of researchers working in Brazil) and, through the personal list of publications and research projects, other research collaborators were identified who were listed as possible participants.

Secondly, governmental institutions with interest in the management of water resources were identified based on previous work (Bracht 2008; Lara 2014; Barcellos et al. 2019a, p. 74). Additionally, other institutions were identified through internet research, including those related to the productive sector and the hospital and pharmaceutical sectors.

The representatives of the selected institutions were divided into 5 groups: decision makers, generally representing local and state government; researchers, belonging to the 4 main local universities; pharmaceutical sector (unions, class councils and institutions representing the category) and representatives from a hospital (healthcare workers appointed by the manager); pharmaceutical industry and finally the water industry, represented by the Parana State Sanitation Company - SANEPAR (a list of institutions and the number of invitees of each group stakeholders can be found in Supplemental Data).

\section{The Prioritization Process}

A workshop was held involving all stakeholders. This was divided into two phases: the first phase sought to identify 5 pharmaceuticals prioritized for monitoring and management to reduce their residues and to justify this selection; in the second phase, possible management objectives and initiatives for pollution control were identified, whereby stakeholders also indicated the stages and temporal scale to implement these. The discussions in both the first part of the event and the second were based on scientific evidence (Figure 1). In the first phase of the event, the 'long list' was sent to participants by email, two weeks before the event. While at the end of the first part of the event, the dynamics of the second phase were explained and participants were given the frame of management initiatives, adapted from the literature (Supplemental Data). Based on this frame, as the 'long list' in first phase, the participants were asked to bring a list of goals that, in their perception, could be achieved by their 
217 own sector to reduce the concentration of pharmaceuticals in rivers. These materials 218 (long list and frame of management initiatives) were useful to guide the discussion and 219 enriched it at the working tables, where individual perceptions could be further 220 developed.

221 Figure 1 - Sequential diagram of the collective approach developed for prioritization on 222 the management of pharmaceutical micropollutants.

In order to allow more effective management of the discussions and to encourage a more productive participation of each participant, the initial group of 55 invitees was divided into 2 subgroups in the first phase of the workshop, maintaining proportionality of each sector in each group of stakeholders. The two subgroups met on November 19 and 20, 2018, respectively for the first phase events. At each subgroup meeting, the guests were divided into four working tables. The composition of the tables was planned so that each table could count on the participation of a representative from each sector, allocated prior to the event with a random number generator (both in the first and second round), although this was not quite achieved as not all invitees attended: each of the subgroup meetings was attended by 17 participants each, totaling 34 guests out of 55 stakeholders initially invited. Once consensus was obtained in working tables, the results were presented and discussed in a plenary session. The second phase of the process occurred on November 27, 2018. This phase followed the same methodology as the previous phase, but with the formation of sectoral working tables, instead of multisectoral negotiation. This phase was designed to be carried out with all 34 stakeholders who participated in the first phase (subgroups 1 and 2), but only 22 participants attended the second phase. Of these 22 participants, 3 had not attended the first phase of the event. The stakeholders this phase represented four sectors and were accordingly arranged at four working tables.

Both in the second and in the first phase of the event, each working table had a mediator / rapporteur. They had the function of leading the discussion, if necessary, and reporting on its most important points. In the two phases of the event, one of the participants at each table was responsible for filling in a standard sheet with the results of the table by consensus. In the plenary sessions there was also a rapporteur. At the start of the plenary session of the first phase of the event, a free discussion was established. In the meantime, the support team calculated the values of the top seven (first round) and top five (second round) - seven and five points were assigned to the first in the ranking each table, six and four to the second and so on - of the four work tables, creating a single ranking for each round. It should be noted that the scoring systems were merely illustrative so that reflection and discussion could be established; consensus was the basic principle of the entire event. In the plenary sessions of the second phase of the event, the most important goal agreed by each sectoral table (first round), the ways to achieve it and the timeframe (second round) were read aloud to allow a moment for reflection and multisectoral discussion. At the end of the second plenary sessions at both the first and the second phase of the event, the Mentimeter ${ }^{\circledR}$ software was used to perceive the individual opinion of the participants.

\section{PRIORITY PHARMACEUTICAL PRODUCTS FOR WASTE MANAGEMENT}


The first result obtained was derived from the individual lists brought in by the invited stakeholders. For the construction of a classification, a scoring system was assigned to the individual lists, following the same logic as those developed for the top 7 and 5 . Scores in individual lists were summed by compound resulting in a ranking (Figure 2). It should be noted that exercise of classification of individual lists was carried out after the meetings, only in an exploratory way, and participants not have access this ranking. The lists were used in the working tables and delivered the end of the event

Figure 2 - Top 10 priority pharmaceuticals of according to the individual perceptions.

A total of 65 different pharmaceuticals were mentioned on the individual lists. Those most frequently prioritized belonged to the following therapeutic groups: hormones, with four compounds (ehinylestradiol, estradiol, estrone and levonorgestrel), two of which were first and second in the ranking; anti-inflammatories (diclofenac and ibuprofen); antibiotics (amoxicillin and ciprofloxacin); an analgesic (paracetamol); a psychotropic (fluoxetine) and a stimulant (caffeine). Ciprofloxacin, which was not on the 'long list', was selected in many individual lists and ranked 11 in this initial exercise.

The results of the first round of negotiation (Figures 3 and 4) - the closed meeting where working tables attempted to identify 7 pharmaceuticals as priorities - show that the second subgroup (Figure 4) of stakeholders had more difficulty to agree on the most important compounds compared to the first subgroup (Figure 3), with the final list of the subgroup 2 showing 13 pharmaceuticals whereas the of subgroup 1 showed only 8 . The score of the first placed in the ranking was significantly lower in the subgroup 2 , and there were also pharmaceuticals tied in the fourth, fifth and seventh position of the final list.

In the subgroup 1 plenary, the focus of the discussions was what pharmaceuticals should be prioritized and what would be the criteria for choosing them. On the other hand, in the subgroup 2, the discussion was focused on the paradox: prioritizing specific pharmaceuticals based on their individual importance or identify markers for the various therapeutic groups. In this subgroup, virtually every working tables agreed that it would be better to prioritize markers rather than specific pharmaceuticals. Perhaps this is the most logical explanation for the greater balance in the list of the priority pharmaceuticals pointed out by subgroup 2 .

Figure 3 - Top 7 priority pharmaceuticals of according to stakeholders (First Round) subgroup 1.

In the plenary session of the round, the results of the prioritization of each working table and the pharmaceuticals with the highest aggregated score (adding up the values of all working tables) were presented for general discussion. After the plenary, the groups returned to the working tables in order rank the top 5 pharmaceuticals, based on the general ranking of the pharmaceuticals prioritized in the first round.

Figure 4 - Top 7 priority pharmaceuticals of according to stakeholders (First Round) subgroup 2. 
With a second round of discussion in the working tables, each table was able to produce a consensual ranking of five of the most important pharmaceutical products for the management of the waters of the region of Curitiba. The results of the second round of discussion were tabulated with the scoring system that was used to present the aggregated results of the four tables working in the plenary (Figure 5).

Figure 5 - Top 5 priority pharmaceuticals for the subgroups 1 and 2 (Second Round).

Subgroup 1 agreed that antibiotics should be included as a group because antibiotic residues may represent important environmental and public health problems. It was agreed that the detection of antibiotics can be done indirectly, measuring the effect of bacterial resistance to pharmaceuticals, since this methodology has a low cost and an easy analytical procedure unlike the chromatographic methods. Ciprofloxacin was the antibiotic most indicated by the stakeholders, because its molecule remains active after treatment (it is persistent). Beta-lactam antibiotics, despite being listed as a priority in the literature, were discarded by stakeholders because they degrade easily in the environment (Mitchell et. 2014; Timm et. 2019). Fluoxetine was not indicated as a priority because, according to stakeholders, there are other pharmaceuticals whose impacts are more relevant. The anti-inflammatory nimesulide, widely used in Brazil, was mentioned by this subgroup in plenary, as it is a molecule that needs to be further studied regarding its potential risks to the environment, but is currently not recognized by the group as a priority. In the end, the subgroup 1 agreed that the order of prioritization was established more by the potential risks to the environment than by frequency of use.

After the plenary session that identified the 5 priority pharmaceuticals for the management in subgroup 1, according to the aggregate score of the work tables (Figure $5)$, a survey was carried out using the software Mentimeter ${ }^{\circledast}$, in which the stakeholders were invited to answer, with their smartphones, a question about their satisfaction with the ranking produced. The results showed a high degree of satisfaction regarding the final ranking: 14 out of the 17 participants answered the question (three participants had to leave before the end of the discussion and so they did not answer the question), whereby four stated they were very satisfied, eight were satisfied, two were not entirely satisfied, and no one answer for the option "unsatisfied" or "very unsatisfied". The two stakeholders who were not entirely satisfied were a representative from the pharmaceutical industry and hospital. For the hospital representative, the dissatisfaction was due to the fact that the management of some priority molecules would require a very specific investment and a more macro view was needed. In the case of one of the representatives of the pharmaceutical industry the dissatisfaction was due to the fact that only two pharmaceuticals prioritized in their individual list were in the top 5 of the group.

In the subgroup 2 plenary, one participant stated that in their perception it seemed reasonable and feasible to introduce legislation requiring monitoring of pharmaceutical micropollutants in urban river waters, with one representative compound for each pharmaceutical group. For him, the monitoring procedures would be feasible financially, since some institutions already have equipment to carry out the measurements. However, this was not the consensus among the various sectors 
represented at the meeting. In the working tables of this subgroup, participants frequently suggested caffeine for inclusion in the list of priority pharmaceuticals, since it is an indicator pharmaceutical for the presence of sanitary effluents, which is the main vehicle of several pharmaceuticals for rivers (Figure 5). Caffeine has been shown to being a good indicator for the presence of other pharmaceutical compounds because, in addition to be a persistent molecule in the environment, it is present in many pharmaceuticals as an auxiliary substance (Daneshvar et al. 2012; Montagner et al. 2014; Baz-Lomba et al. 2016; Alygizakis et al. 2016; Korekar et al. 2019). Another substance mentioned that could be used as an indicator was Carbamazepine: some experts have already used this compound as a monitoring alternative to Caffeine since it is also a persistent molecule and widely used in the pharmaceutical industry (Guo and Krasner, 2009; Wang and Wang, 2017; Dinis et al. 2017; Dvory et al. 2018). It was discussed by the group that it might be interesting to include as a priority the pair of anti-inflammatory pharmaceuticals, diclofenac and ibuprofen, as both are widely used at all times of the year.

Again, with use of the software Mentimeter ${ }^{\circledR}$, applying to the audience a final question about the overall satisfaction with the aggregated prioritization results (Figure $5)$, most of the participating stakeholders agreed with the final ranking. Of the 17 stakeholders 9 answered the question (eight participants had to leave before the end of the discussion and so they did not answer the question), where seven respondents said they were satisfied and two indicated the option "I am not entirely satisfied" with the priorities highlighted by the group. For stakeholders who were not entirely satisfied were a representative from academia and a hospital. For the hospital representative the dissatisfaction was because two anti-inflammatory pharmaceuticals (ibuprofen and diclofenac) on the priority list would be too much - should be one or the other. In place of one, his would include an antineoplastic. For the academic stakeholder the dissatisfaction was because triclosan should be on the medication prioritization list, as it is an endocrine disruptor, bioaccumulative and in many countries, such as the USA and some European countries, it is already banned, while in Brazil it is still used as a preservative in hygiene products (shampoos, soaps, etc).

There was a clear similarity (Figure 5) between the two lists of 5 priority compounds as identified in the two subgroups, which demonstrates the validity of the method since the stakeholders who participated in the two subgroups were different, with no contact between the groups.

Table 1 shows the final score of the ranking pharmaceuticals identified as priorities by the stakeholders in this first phase of the workshop and the justifications that were given for their prioritization. Ethinylestradiol, ibuprofen, ciprofloxacin and diclofenac were identified by both subgroups as the four most important pharmaceuticals for water management. Regarding the fifth priority pharmaceutical, the hormone estradiol had a higher score (8), however, caffeine (7) and fluoxetine (6) had a very close score. Therefore, there are still doubts about the fifth substance to be prioritized.

Table 1 - Priority pharmaceuticals for water management according to the stakeholders' perception. 
*Ecotoxicological LOEC - Lowest Observed Effect Concentration.

\section{FEASIBLE MANAGEMENT GOALS}

The feasible goals for the management of the pharmaceutical micropollutants in the Curitiba region were discussed at the second phase of the workshop that took place on November 27, 2018. As mentioned, participation at this event was significantly lower, with only 22 participants out of about 34 expected stakeholders in attendance. One important and significant lack was the absence of the government sectoral group (policy makers): no representative of that sector attended the event.

Not surprisingly, the individual goals were quite diverse, although they pointed in converging directions. Frequently suggested individual goals were:

1. The full implementation of a drug take-back program of expired or obsolete pharmaceuticals. The scope of this initiative varied in the lists, which sometimes indicated a state scale of coverage (in the cities of Parana State), sometimes local (pharmacies and medical centers in Curitiba) and sometimes sectoral (encompassing pharmaceutical distributors);

2. Periodic monitoring of pharmaceutical micropollutants in water supply and river basins. With regards to monitoring, the individual lists pointed out two directions: a) to monitor those of greater consumption; b) to create a working group to discuss and make feasible this activity, in terms of infrastructure and equipment, partnerships, costs and analytical methodologies;

3. Development and testing of efficient treatments for the removal of priority pharmaceutical micropollutants in water and sewage. The scope of the proposal was to find efficient treatment for water industry, responsible for municipal water and sewage treatment, and pharmaceutical industries. In this goal, it was evident that participants saw this as academic research at this stage, because little was thought to be known about the viable and effective techniques of removal of these compounds;

4. Multisector partnerships: academia, pharmaceutical sector, pharmaceutical and water industry as well, for the identification of priority compounds, development of analytical methodologies and the removal of these compounds;

5. Universalization of sanitation systems including sewage networks and treatment plants;

6. Implement a limit concentration for priority pharmaceutical micropollutants in rivers and water supply systems in the coming years;

7. Evaluation of the internal processes of the pharmaceutical industry to reduce the generation of waste and consequently lower the concentration of emerging micropollutants in the effluents;

8. Environmental education for the correct disposal of pharmaceuticals, rational use, and reduction of self-medication: this educational process would occur through recommendations on the packaging of pharmaceuticals and advertisements (newspapers, television, bus stops, etc.). 
In the individual goals, as well as in those discussed at the sectoral working tables, the absence of public policy was a clear consequence of the absence of the government sector.

The lists of individual goals presented a preview of what would be discussed at the sectoral tables, but the robustness and originality of the goals discussed at the table far outstripped those highlighted by the individual goals.

The general discussion on management goals was quite comprehensive bringing several new elements to the discussion. From the hospital and pharmaceutical perspective, addressing and solving the problem of pharmaceuticals in the environment is very difficult, since much of the problem is related to human excretion, requires specialized treatment plant and cannot be solved by the sector.

Although reconsidering of packaging sizes of pharmaceuticals is not in the sectoral goals, this goal was highlighted in the general discussions as a simple and efficient management measure, which in Brazil is not considered, there is no legislation that requires this of industry. It is known that packaging size can influence consumption, better serving users' needs and preventing the generation of unused and expired pharmaceuticals (BIO Intelligence Service 2013), for this some insdustries have already been working on this direction. The pharmaceutical sector stressed that the federal regulation should be modified in favor of this measure. In this way, the pharmaceuticals would not be stored unused at home.

Collection of expired or discontinued pharmaceutical products was a muchmentioned and discussed management initiative, both in sectoral goals and general discussions. Although there is clear progress in this regard, Brazil is still in an early phase of this management initiative (Aquino et al. 2018; Barcellos et al. 2019, p. 126; Rebehy et al. 2019). The feasible management goals that were agreed upon by each one of the four sectors participating in the event are presented in Tables 2, 3, 4 and 5.

Table 2 - Distributors and pharmaceutical industries goals.

*Goal nominated by sector as more important.

Table 3 - Water industry goals.

*Goal nominated by sector as more important.

Table 4 - Pharmaceutical and hospital goals.

*Goal nominated by sector as more important.

Table 5 - Academic goals.

* Goal nominated by sector as more important.

The pharmaceutical sector stressed that through the Parana State pilot drug take-back program, which ended in 2017, 9.6 million kilograms of unused pharmaceuticals were collected. The participation of drugstores in Foz do Iguaçu, a city around $600 \mathrm{~km}$ far from Curitiba, where the population's adherence to the project was high, was highlighted as a success. In Paraná, the law that regulates the drug take-back program came into force in July 2018, with, 270 collection points in operation and the 
472 goal for 2019 is that further 500 points be installed. As State legislation covering drug 473 take-back programmes is recent, the project under development is considered as pilot and is still in the test phase. The collection of pharmaceuticals is carried out for 60 consecutive days at each location, after which the collection point is moved to another pharmacy. Collected pharmaceuticals are transported to an incineration plant in São Paulo, with support from the Union of Pharmaceutical Products Industry in the State of São Paulo (SINDUSFARMA).

The pharmaceutical industry, on the other hand, reported having developed a separate, smaller scale project support with Union of the Chemical and Pharmaceutical Industries of the State of Paraná (SINQFAR-PR) whereby 60 pharmaceutical collection points have been established on a permanent basis in the State of Paraná. In the State of São Paulo, laws regulating the drug take-back program are of municipal scope, but are at a more incipient stage than what occurs in Parana State. The Federal Law Project that will be regulating this topic, and is currently in discussion in the National Congress, was also cited as essential for the expansion of drug take-back in Brazil.

The representatives of the water industry suggested to the group, especially to the representatives of the pharmaceutical sector, that it would be useful to include in product packaging information about the impact of pharmaceutical residues on the environment and on human health.

Participants from all sectors noted the absence of government stakeholders in the discussion. This constituted a gap in the intersectoral dialogue, as government institutions have a fundamental role in the introduction of public policies. It was noted that many of the measures targeted by the sectors can only be implemented if there is effective participation of the government. The need for synergy among sectors (government, water industry, pharmaceutical industries and distributors, hospitals and pharmacies, and academia sectors) was evident in the discussion for effective progress in the management of pharmaceutical micropollutants in Brazil.

The water industry, represented by the Parana State Sanitation Company (SANEPAR), showed that these collaborative actions are indispensable for the sector due to the need for research technological advances that can only be developed with at least the support of academia. Its representatives also added that they would be very interested to open a more effective dialogue with the pharmaceutical sector to facilitate information exchange and enhance understanding of risk from pharmaceutical residues to the environment and to human health.

Another discussion that was emphasized by the representatives of the water industry, considered the importance of establishing specific legislation to establish the monitoring of pharmaceuticals along with the establishment of safe concentration limits in river waters. A government representative in the first phase of the event also positioned himself in a favorable way to this, arguing that the periodic monitoring of these molecules is already financially viable, thus feasible.

At the end of this second phase of discussions, Mentimeter ${ }^{\circledast}$ was used to assess stakeholders' perception regarding the timeframe necessary achieve a similar level of 
514 control over pharmaceutical residues in the environment as is the case in some developed countries in Europe (United Kingdom, Germany, Netherlands, etc). Twelve out of the 22 participants answered the question (ten had to leave before the end of the plenary). Of the respondents, one answered that it would take " 5 years", five answered "5 to 10 years", another 5 indicated that it would take "10 to 20 years" and one responded "more than 20 years". At this point, the pharmaceutical sector spoke up and said that the pharmaceutical industry must modify its production system in order to reduce pharmaceuticals in the environment. Another point touched was that the treatment of sewage is significant and should be prioritized because it reduces the pharmaceuticals in the environment.

\section{4}

525

526

527

528

529

530

531

532

533

534

535

536

537

538

539

540

541

542

543

544

545

546

547

548

549

550

551

552

553

554

555

556

\section{CONCLUSION}

The compounds prioritized (seven clearly had more importance) by the stakeholders in the workshop reflect the sectoral interests related to pharmaceutical pollution in the water and its management. The multidisciplinarity and multisectorality of the stakeholders present at the meeting ensured a comprehensive view of the problem, indicating which are the most important pharmaceuticals for management in the region of Curitiba and why they should be prioritized. On a national scale, these compounds are also likely to be important, but it is necessary to make efforts of prioritize in other regions because each region will have a different consumption pattern and, consequently, a different pollution pattern.

The management goals are also important to think about and act towards the management of pharmaceutical micropollutants on the national scale and these are more generalizable than a list of priority substances. The multisectoral discussion about feasible actions showed that some initiatives priority have already started but are still emerging, as is the case of drug take-back program. Raising awareness amongst the population on the correct disposal of pharmaceuticals was defined as a priority goal, as were the technical and political aspects of implementation of the drug take-back program in Brazil. This issue is still a major challenge on a national scale and, due to its shared attribution, it is necessary to construct multisectoral networks and also have the participation of the population. Monitoring efforts to characterize the behavior of pharmaceuticals in the sanitation cycle and the creation of a permanent multisectoral environment for discussion on pharmaceutical micropollutants were the other two management goals prioritized. The new fronts of action and the challenges of each sector were also important elements of multisectoral discussion for enabling each sector to recognize the complexity of the problem and understand the need for a collective approach of problem, as already occurs in Europe (NOPILLS, 2015).

However, the workshop represented an important initial step towards the management of pharmaceutical micropollutants in the Curitiba region and Brazil, being the first meeting with this multisectoral character in the country to discuss this type of pollution. In addition to the knowledge produced collectively, the most important legacy of this event was the formation of a network to discuss this problem and advance its management. The 37 stakeholders who participated in the event have great engagement in their sectors and relevant capacity for action. It is hoped that the 
established network can be maintained and work collaboratively for the management of pharmaceutical micropollutants, as is it done successfully in Europe.

The methodology used to conduct the workshop reached its objectives, producing collective knowledge in an interactively way, as well as informing and connecting people towards a common goal. This approach has shown promise for developing countries, such as those in Latin America, which are general still taking the first steps towards managing this kind of problem.

\section{SUPPLEMENTAL DATA}

The Supplemental Data contains: 1) the list with groups, institutions, total number of stakeholders preselected and those who participated of the event and; 2 ) the 'long list' of initial pharmaceutical micropollutants made available to the stakeholders; 3) frame of management initiatives made available to the stakeholders.

\section{REFERENCES}

Alygizakis NA, Gago-Ferrero P, Borova VL, Pavlidou A, Hatzianestis I, Thomaidis NS. 2016. Occurrence and spatial distribution of 158 pharmaceuticals, drugs of abuse and related metabolites in offshore seawater. Sci Total Environ, 541, 1097-1105.

Aquino S, Spina GA, Zajac MAL, Lopes EL. 2018. Reverse Logistics of Postconsumer Medicines: The Roles and Knowledge of Pharmacists in the Municipality of São Paulo, Brazil, Sustainability, MDPI, Open Access Journal, vol. 10(11), pages 1-17, November.

Ashley C, Currie C. 2009. The Renal Drug Handbook. 3ed. Oxford (England): Radcliffe Publishing. 814 p.

Barcellos DS, Bollmann HA, Azevedo JCR. 2019a. Gestão de micropoluentes farmacêuticos em rios urbanos: um estudo do caso dos contraceptivos orais na bacia hidrográfica do Rio Belém. 1. ed. Riga (Latvia): OmniScriptum Publishing Group, v. 1. 229 p.

Barcellos DS, Bollmann HA, Azevedo JCR. 2019b. Prioritization of pharmaceuticals in urban rivers: the case of oral contraceptives in the Belém River basin, Curitiba / PR, Brazil. Revista Ambiente e Agua, v. 14, p. 1-13.

Baz-Lomba JA, Salvatore. S, Gracia-Lor E, Bade R, Castiglioni S, Castrignana E, Causanilles A, Hernandez F, Kasprzyk-Hordern B, Kinyua J, Mccall A, Van Nuijs A, Ort C, Plosz BG, Ramin P, Reid M, Rousis NI, Ryu Y, De Voogt P, Bramness J, Thomas K. 2016. Comparison of pharmaceutical, illicit drug, alcohol, nicotine and caffeine levels in wastewater with sale, seizure and consumption data for 8 European cities. BMC Public Health 16, 1035 (2016).

Bernareggi A. 1998. Clinical pharmacokinetics of nimesulide. Clin Pharmacokinet. 1998 Oct; 35 (4): 247-74.

BIO Intelligence Service. 2013. Study on the environmental risks of medicinal products. Paris: France. Final Report prepared for Executive Agency for Health and Consumers. 
Böger B, Amaral B, Silveira PL, Wagner R, Peralta-Zamora PG, Gomes EC. 2018. Determination of carbamazepine and diazepam by SPE-HPLC-DAD in Belém river water, Curitiba-PR/Brazil. Revista Ambiente e Agua, v. 13, p. 1-12

Böger B, Tonin FS, Peralta-Zamora PG, Wagner R, Gomes EC. 2015. Micropoluentes emergentes de origem farmacêutica em matrizes aquosas do Brasil: uma revisão sistemática. Ciência e Natura, v. 37, p. 725-739.

Bracht CC. 2008. Instrumentos jurídicos e programas de gestão dos recursos hídricos e seus reflexos na qualidade das águas na Bacia Hidrográfica do Rio Belém. Dissertation (Master in Urban Management) Pontifical Catholic University of Paraná, Curitiba.

Brazil - Ministry of Health. 2017. Consolidation Ordinance No. 5, of September 28, 2017. Consolidation of the rules on actions and health services of the Unified Health System. Official Diary of the Union, Brasília, DF, september 28, 2017.

Brazil - National Council for the Environment (CONAMA). 2005. Resolution No. 357 of March 17, 2005. Provides for the classification of bodies of water and environmental guidelines for their classification, as well as establishing the conditions and standards for the discharge of effluents, and other measures. Official Diary of the Union, Brasília, DF, 17 march 2005.

Brazil. 1988. Constitution of the Federative Republic of Brazil. Brasília, DF, 5 october 1988.

Cunha DL. 2014. Evaluation of the consumption pattern of $17 \alpha$ - ethinylestradiol in the municipality of Santa Maria Madalena - RJ. Dissertation (Master in Public Health) Fundação Oswaldo Cruz, Rio de Janeiro.

Daneshvar A, Aboulfadl K, Viglino LG, Broséus R, Sauvé S, Madoux-Humery A, Weyhenmeyer GA, Prévost M. 2012. Evaluating pharmaceuticals and caffeine as indicators of fecal contamination in drinking water sources of the Greater Montreal region. Chemosphere, 88 1, 131-9.

Dias RVA. 2014. Avaliação da ocorrência de microcontaminantes emergentes em sistemas de abastecimento de água e da atividade estrogênica do estinilestradiol. Dissertation (Master in Sanitation, Environment and Water Resources) Federal University of Minas Gerais, Belo Horizonte.

Dinis TB, Passos H, Lima DL, Sousa AC, Coutinho JA, Esteves VI, Freire MG. 2017. Simultaneous extraction and concentration of water pollution tracers using ionic-liquidbased systems. Journal of chromatography. A, 1559, 69-77.

Doerr-Macewen NA, Haight ME. 2006. Expert stakeholders 'views on the management of human pharmaceuticals in the environment. Environ. Manage. v. 38 p. 853-866.

Dvory NZ, Livshitz Y, Kuznetsov M, Adar E, Gasser G, Pankratov I, Lev O, Yakirevich A. 2018. Caffeine vs. carbamazepine as indicators of wastewater pollution in a karst aquifer. Hydrol. Earth Syst. Sci., 22, 6371-6381.

[EMC] Eletronic medicines compendium. 2017. Datapharma. [accessed 2017 nov 10]. https://www.medicines.org.uk/emc/. 
Gilbert N. 2012. Drug-pollution law all washed up. Nature, v. 491, n. 7425, p. 503-504.

Guo YC, Krasner SW. 2009. Occurrence of Primidone, Carbamazepine, Caffeine, and Precursors for N-Nitrosodimethylamine in Drinking Water Sources Impacted by Wastewater.Journal of the American Water Resources Association, 45, 58-67.

Halling-Sørensen B, Nielsen SN, Lanzky PF, Ingerslev F, Lutzheft HCH, Jørgensen SE. 1998. Occurrence, Fate and Effects of Pharmaceutical Substances in the Environment A review. Chemosphere, v. 36, n. 2, p. 357-393.

Helwig K, Hunter C, MacLachlan J, McNaughtan M, Roberts J, Cornelissen A, Dagot C, Evenblij H, Klepiszewski K, Sven L, Nafo I, McArdell C, Pahl O. 2013. Micropollutant point sources in the built environment: identification and monitoring of priority pharmaceutical substances in hospital effluents. Journal of Environmental \& Analytical Toxicology. 3, 4, p. 1-1010 p.

Helwig K, Hunter C, McNaughtan M, Roberts J, Pahl O. 2016. Ranking Prescribed Pharmaceuticals in Terms of Environmental Risk: Inclusion of Hospital Data and the Importance of Regular Review. Environmental Toxicology and Chemistry 35.4: 10431050 .

Helwig KPM. 2018. Stewardship approaches to reducing health-care contaminants. In: Boxall A, Kookana R. Health Care and Environmental Contamination. Oxford (England): Elsevier, pp 199-223.

[IBGE] Brazilian Institute of Geography and Statistics. 2016. IBGE releases population estimates for municipalities in 2016. [accessed 2020 jan 5].https://agenciadenoticias.ibge.gov.br/agencia-sala-de-imprensa/2013-agencia-denoticias/releases/9497-ibge-divulga-as-estimativas-populacionais-dos-municipios-em2016

[IBGE] Brazilian Institute of Geography and Statistics. 2019. Population estimate for 2019. [accessed 2020 jan 5]. http://web.archive.org/web/20190915091638/https://cidades.ibge.gov.br/brasil/pr/curitib a/panorama

Ide AH, Cardoso FD, Santos MM, Mizukawa A, Kramer RD, Azevedo JCR. 2013. Use of Caffeine as an Indicator of Domestic Sewage Contamination in the Upper Iguaçu Basin. Brazilian Journal of Water Resources, v. 18, p. 201-211.

Johnson AC, Williams RJ. 2004. A Model To Estimate Influent and Effluent Concentrations of Estradiol, Estrone, and Ethinylestradiol at Sewage Treatment Works. Environ. Sci. Technol., V.38, n.13, p.3649-3658.

Korekar G, Kumar A, Ugale C. 2019. Occurrence, fate, persistence and remediation of caffeine: a review. Environmental Science and Pollution Research. doi:10.1007/s11356019-06998-8

Kramer RD, Ide AH, Santos MM, Oliveira LJ, Mizukawa A, Azevedo JCR. 2015. Determination of anti-inflammatory drugs in water and sediment and their relationship with water quality in the Alto Iguaçu basin, Curitiba-PR. Brazilian Journal of Water Resources, v. 20, p. 657-667. 
676 Kümmerer K. 2009. The presence of pharmaceuticals in the environment due to human 677 use - present knowledge and future challenges. Journal of Environmental Management, 678 v. 90 , p. $2354-2366$.

679 Küster A, Adler N. 2014. Pharmaceuticals in the environment: scientific evidence of risks 680 and its regulation. Philos. Trans. R. Soc. Lond. B. Biol. Sci. 369: 1656.

681 Lara MVR. 2014. Análise crítica de programas de revitalização de rios urbanos na bacia 682 hidrográfica do Rio Belém em Curitiba - PR. Dissertation (MSc in Urban and Industrial 683 Environment) - Technology Sector, Federal University of Paraná, Curitiba.

684 Lima DRS, Tonucci MC, Libanio M, Aquino SF. 2017. Pharmaceuticals and endocrine 685 disrupting compounds in Brazilian waters: occurrence and removal techniques. Eng. 686 Sanit. Ambient. vol.22, n.6, pp.1043-1054.

687 Lucena WS. 2013. Drug 17 $\alpha$-stinylestradiol: its possible effects on human and animal 688 health through environmental exposures. 2013. Course Conclusion Paper (Specialization 689 in Pharmaceutical Industrial Technologies) Oswaldo Cruz Foundation, Rio de Janeiro.

690 Macedo J. 2013. Planning a Sustainable City: The Making of Curitiba, Brazil. Journal of 691 Planning History, 12, 334-353.

692 Mega VP. 2010. Sustainable Cities for the Third Millennium: The Odyssey of Urban 693 Excellence. New York (USA): Springer. 248p.

694 Merton RK. 1988. The Matthew Effect in Science, II: Cumulative advantage and the 695 symbolism of intellectual property. ISIS. 79 (4): 606-623.

696 Mitchell SM, Ullman JL, Teel AL, Watts RJ. (2014). pH and temperature effects on the 697 hydrolysis of three $\beta$-lactam antibiotics: Ampicillin, cefalotin and cefoxitin. Science of 698 The Total Environment, v. 466-467, p. 547-555.

699 Montagner CC, Umbuzeiro GA, Pasquini C, Jardim WF. (2014). Caffeine as an indicator 700 of estrogenic activity in source water. Environmental Science-Processes \& Impacts, v. 701 16, p. 1866-1869.

702 NOPILLS. 2015. noPILLS Report. [accessed 2018 may 3]. www.no703 pills.eu/conference/BS_NoPills_Final\%20Report_long_EN.pdf

704 Osawa RA, Ide AH, Sampaio NMFM, Azevedo JCR. 2015. Determination of 705 Antihypertensive Drugs in Surface Water in the Metropolitan Region of Curitiba. 706 Brazilian Journal of Water Resources, v. 20, p. 1039-1050.

707 Owen R, Jobling S. 2013. Ethinyl oestradiol: bitter pill for the precautionary principle. 708 In: [EEA] Europe Environmental Agency. Late Lessons from Early Warnings: Science, 709 Precaution, Innovation. Copenhagen (Denmark): EEA. p. 311-339.

710 Qian F, He M, Song Y, Tysklind M, Wu J. 2015. A bibliometric analysis of global 711 research progress on pharmaceutical wastewater treatment during 1994-2013. 712 Environmental Earth Sciences, 73(9), 4995-5005. 
Rebehy PCPW, Lima SAS, Novi JC, Salgado AP. 2019. Reverse logistics systems in Brazil: Comparative study and interest of multistakeholders. Journal of Environmental Management, 250, 109223.

Reis EO, Foureaux AFS, Rodrigues JS, Moreira VR, Lebron YAR, Santos LVS, Amaral MCS, Lange LC. 2019. Occurrence, removal and seasonal variation of pharmaceuticals in Brasilian drinking water treatment plants. Environmental Pollution. V. 250, p. 773781.

[SANEPAR] Paraná Sanitation Company. 2013. SAIC Master Plan: Integrated Water Supply System of Curitiba and Metropolitan Region. Curitiba (Brazil): Sanepar.

Santos LH, Araújo AN, Fachini A, Pena A, Delerue-Matos C, Montenegro MCBSM. 2010. Ecotoxicological aspects related to the presence of pharmaceuticals in the aquatic environment. J Hazardous Materials, v. 175, p. 45-95.

[SNIS] National Sanitation Information System. 2018. SNIS - Historical Series - Ministry of Cities, 2018. [accessed 2019 oct 20]. http://app.cidades.gov.br/serieHistorica

Tiedeken EJ, Tahar A, McHugh B, Rowan N J. 2017. Monitoring, sources, receptors, and control measures for three European Union watch list substances of emerging concern in receiving waters - A 20 year systematic review. Sci Total Environ, 574, 1140-1163.

Timm A, Borowska E, Majewsky M, Merel S, Zwiener C, Bräse S, Horn H.(2019). Photolysis of four $\beta$-lactam antibiotics under simulated environmental conditions: Degradation, transformation products and antibacterial activity, Science of The Total Environment, Volume 651, Part 1, p 1605-1612.

Wang S, Wang J. 2017. Carbamazepine degradation by gamma irradiation coupled to biological treatment. Journal of hazardous materials, 321, 639-646.

Wiki Pharma. 2018. Wiki Pharma's database. [accessed 2018 may 10]. http://www.wikipharma.org/welcome.asp 